\title{
ANÁLISE DE POLÍTICAS PÚBLICAS: UMA \\ REVISÃO DA LITERATURA SOBRE O PAPEL \\ DOS SUBSISTEMAS, COMUNIDADES \\ E REDES
}

\author{
Ana Cláudia niedhardt CApella \\ FELIPE GONÇALVES BRASIL
}

\section{RESUMO}

Das abordagens tradicionais à sua incorporação em recentes modelos de análise da produção de políticas, os subsistemas têm ganhado papel de destaque na literatura internacional de políticas públicas. O objetivo deste artigo é apresentar a construção dos conceitos de subsistemas, comunidades e redes e a forma como os modelos teóricos mais recentes se apoiam nessas subunidades como lócus de interação entre diferentes atores, instituições e ideias para a análise do processo de políticas públicas.

Palavras-chave: subsistemas; politicas públicas; análise de politica; subsistema de políticas.

\section{ABSTRACT}

From theoretical approaches to its incorporation in recent models of policies analysis, the subsystems have gained a prominent role in the international literature of public policies. The objective of this paper is to present the construction of the concepts of subsystems, policy communities and policy networks and check how the most recent theoretical models use these subunits as the "locus" of interaction between different actors, institutions and ideas to analyze the policy process.

KEYWORDS: subsystems; public policy; policy analysis; policy subsystems.

\section{INTRODUÇão}

A literatura sobre subsistemas foi inicialmente desenvolvida no contexto dos estudos da ciência política estadunidense em meados dos anos 1950. Inseridos num momento histórico marcado pelo embate teórico entre as hegemônicas perspectivas elitista e pluralista de análise do processo político, os estudos de subsistemas surgem como uma nova forma de compreensão da formação e atuação do sistema político americano. Nos estudos recentes, o conceito de subsistema 
de políticas (policy subsystem) tem ocupado espaço central em diversos modelos teóricos, tendo sido considerado como unidade de análise privilegiada em abordagens recentes sobre o processo de políticas públicas.

Para a compreensão desse conceito, é preciso contextualizá-lo na perspectiva sistêmica dos estudos conduzidos no campo da ciência política nos Estados Unidos. Nesse contexto, a literatura tem destacado três dimensões essenciais do sistema político: o macrossistema, o microssistema e os subsistemas (Thurber, 1996). A primeira dimensão, os macrossistemas (macro policy systems), refere-se às decisões que afetam diretamente uma política pública ou a estrutura de poder em torno dela. Essa dimensão é caracterizada por um alto escopo de conflito, uma vez que as decisões geram impactos visíveis sobre a sociedade o o sistema político.Além disso, os macrossistemas são compostos de um grande número de participantes com múltiplos interesses. São decisões que envolvem as principais políticas de um governo, como as negociações sobre a aprovação final do orçamento, sobre a política macroeconômica, cortes orçamentários, entre outros. Essas questões são, frequentemente, controversas e de alta visibilidade, fazendo com que as decisões tomadas afetem muitos indivíduos e despertem, assim, a atenção da mídia e da opinião pública. A tomada de decisão política nos macrossistemas traz para o processo de produção de política novos atores e tomadores de decisão de alto nível, produzindo novas políticas que não poderiam ser formuladas em outra dimensão.

No outro extremo, os microssistemas (micro policy systems) envolvem decisões que geralmente não despertam a atenção do público. Neles são tomadas decisões baseadas em alta complexidade técnica, envolvendo um número bastante reduzido de tomadores de decisão que procuram restringir o acesso de outros participantes. São questões que raramente aparecem nos debates eleitorais, na imprensa e que ficam restritas aos técnicos dentro da burocracia pública. Os microssistemas são caracterizados por um baixo e personalizado escopo de conflito e por baixo número de participantes envolvidos, o que acarreta um processo de decisão centralizado e praticamente invisível.

Por fim, entre o macrossistema e o microssistema, situam-se os subsistemas (policy subsystems). Os subsistemas são compostos de um número limitado de atores e instituições, geralmente reunidos em grupos mais ou menos coesos, que se especializam e direcionam seus esforços para algumas questões específicas em relação a uma política. Como resultado da divisão do trabalho e da especialização da burocracia, as áreas funcionais, como educação, saúde, transporte, meio ambiente, entre outras, são compostas de arranjos institucionais e atores que tendem a se aglutinar em torno de programas ou interesses específicos, no que é chamado pela literatura internacional de "policy 
[1] Policy domain pode ser definido como "a área substantiva de política pública sobre a qual os participantes na produção da política competem e fazem concessões para chegar a um acordo, tais como o domínio da política ambiental o domínio da política de saúde" (Birkland, 2005, p. 97). domain"1. O estudo do processo de produção de políticas públicas tem revelado que, para a análise de uma política, não basta observar a organização pública encarregada formalmente de sua formulação, implementação ou avaliação. Para a análise de uma política, a literatura recente tem privilegiado a análise dos subsistemas, espaços que têm recebido diferenciados tratamentos teóricos ao longo das últimas décadas. Tal entendimento acerca dos subsistemas como dimensão integrante do grande sistema político tem permitido o desenvolvimento de uma extensa bibliografia em torno desses arranjos, suas características, composição e impacto na produção de políticas públicas.

Entretanto, o conceito de subsistema de políticas éobjeto de intensa discussão teórica, principalmente quando justaposto a conceitos relacionados, como os de comunidades de políticas (policy communities), redes de políticas públicas (policy networks) e redes temáticas (issue networks). Tais conceitos podem contribuir significativamente para análises sobre os processos de mudança em políticas públicas, sobretudo em perspectivas que consideram o papel dos atores por meio de suas ideias, seus conhecimentos e interesses. (Baumgartner e Jones, 1993; Sabatier Jenkins-Smith, 1993; Howlette Ramesh,1998;2003).

O presente estudo tem como objetivo apresentar a construção teórica em torno da ideia de subsistemas, comunidades e redes de políticas públicas, bem como discutir a incorporação e o desenvolvimento desses conceitos em modelos teóricos recentes. Para tanto, na primeira seção apresentaremos o histórico acerca da construção e ressignificação dos conceitos de subsistemas, comunidades e redes, categorias mais recentemente utilizadas para a análise de políticas e que promovem avanços significativos em relação a enfoques tradicionais. As três seções seguintes são dedicadas à análise da apropriação desses conceitos por três modelos recentes desenvolvidos no campo de políticas públicas: o modelo de múltiplos fluxos (multiple streams), o modelo de equilíbrio pontuado (punctuated equilibrium) e o modelo das coalizões de defesa (advocacy coalitionframework). Tais modelos tomam esses conceitos como base, embora analisem de forma distinta suas influências no processo político. $\mathrm{Na}$ sequência, apresentaremos estudos de caso baseados nesses modelos e que permitem observar a aplicação dos conceitos como parte fundamental dessas lentes teóricas, operacionalizando a relação entre atores, instituições, ideias e mudanças em políticas públicas. Por fim, serão apresentadas as principais conclusões sobre o estudo e perspectivas para investigações posteriores.

BREVE HISTÓRICO DOS ESTUDOS SOBRE SUBSISTEMAS, REDES E COMUNIDADES

Diversos autores procuraram analisar a dinâmica dos subsistemas e o padrão de relacionamento dos atores participantes nessa dimen- 
são do processo de políticas públicas. Uma das primeiras análises a respeito dos subsistemas pode ser encontrada no trabalho de Ernest Griffith (1939) sobre o que o autor denominou policy whirlpools, ou centros de atividades focalizados em questões específicas. Mais tarde, a noção de "subgoverno" (subgovernment), definido como "pequenos grupos de atores políticos, tanto governamentais como não governamentais, que se especializam em áreas temáticas específicas" (Ripley e Franklin, 1984, p.7), aponta para a existência de grupos de atores envolvidos em processos rotineiros de tomada de decisão em uma determinada área de política e que podem permanecer ativos durante longos períodos de tempo.

Tido como o primeiro autor a definir propriamente o conceito de subsistemas, J. Leiper Freeman (1955) define um subsistema como o padrão de interações entre o conjunto restrito de participantes envolvidos na tomada de decisões em uma área específica das políticas públicas. Opondo-se à perpectiva pluralista, cuja definição se dá pelas "formas plurais de poder", o autor observa padrões de interação existentes entre pessoas-chave internas ao Executivo, líderes de comissões do Congresso e outros atores, especialmente grupos de interesse. De acordo com Freeman:

[Este estudo] defendeu a utilização desse tipo de abordagem analítica combase no fato de que o estudo do processo nacional de produção de politicas no nivel institucional mais geral do Congresso, do governo e dos partidos politicos nem sempre fornece a compreensão mais significativa dos fatores decisivos. [...] a diversidade social, a multiplicidade de tipos de grupos especiais de pessoas que promoveme defendem valores particulares na vida americana, resulta em concentração seletiva do interesse público e da atenção na politica. (Freeman, 1955, p. 265)

Focalizando as relações entre esses grupos de atores na formulação de políticas públicas no governo americano, seu estudo buscou demonstrar uma maneira útil de examinar o processo político, revelando a existência de subunidades (subsistemas) como lócus do processo de discussão de temas específicos, construção de problemas públicos e formulação de soluções. Nos subsistemas, esse grupo de atores, que podem ser servidores públicos, grupos de interesse, pesquisadores acadêmicos, membros do Legislativo, representantes de governos locais, entre outros, estabelecem redes de relacionamento e utilizam estratégias de persuasão e barganha de forma a privilegiar seus interesses.

A análise dos subsistemas também levou à noção dos "triângulos de ferro", abordagem que rompe com a perspectiva pluralista sobre a produção de políticas públicas dominante nos anos 1950 e 1960 nos 
Estados Unidos. Pautados em relações baseadas no intercâmbio de favores de mútuo interesse, três atores - grupos de interesses, parlamentares e burocratas - controlariam o processo de produção de políticas, excluindo a possibilidade de participação de outros atores. Nesse sentido, há uma significativa mudança na concepção sobre os principais atores e resultados do processo de produção de políticas. A abordagem do triângulo de ferro, ao evidenciar a troca de favores e de interesses privados mútuos como propulsor da policymaking, desconsidera a existência da luta de grupos de interesses difusos, potencializando, assim, o papel de legisladores, burocratas, agências regulatórias e grupos de interesse, tornando-os atores capazes de influenciar a agenda do governo a seu favor (Peters, 1986).

Uma das críticas mais incisivas à ideia de "triângulos de ferro" foi elaborada por Heclo, no final dos anos 1970. Para o autor, o conceito seria incapaz de explicar as conexões entre administração e política.

[... ] o conceito de triângulo de ferro não é tanto errado quanto édesastrosamente incompleto [...]. Preocupados em tentar encontrar os poucos atores verdadeiramente poderosos, os observadores tendem a ignorar o poder e a influência que surgem porfora das configurações através das quais decisores políticos se movem e fazem acordos entre si. Olhando para os triângulos de controle restritos, tendemos a não ver as redes bastante abertas de pessoas que cada vez mais influenciam o governo. (Heclo, 1978, p. 88)

Heclo propõe um olhar mais atento sobre os diferentes interesses em jogo, numa visão da relação entre diferentes grupos sociais mais pluralista do que a visão elitista, presente na ideia do "triângulo de ferro". O autor propõe, alternativamente, o enfoque em "redes de temáticas", ou "issue networks".

Olhando para os poucos que são poderosos, tendemos a ignorar os muitos cujas redes de influência induzem e orientam o exercício do poder. Essas redes, ou o que eu chamarei de "redes temáticas", são particularmente relevantes para as politicas de bem-estar altamente complexas e confusas que foram realizadas nos últimos anos. (Heclo, 1978, p.102)

Enquanto o conceito de "triângulos de ferro" parte do pressuposto da existência de um grupo pequeno de participantes autônomos e relativamente estáveis, reunidos de forma a exercer estrito controle sobre programas públicos que afetassem seus interesses econômicos, as issue networks envolveriam uma quantidade maior de participantes, que se relacionariam em diversos níveis de comprometimento e dependência. Nessas redes, a permanência dos grupos seria mais fluida e menos estável, no sentido de que os grupos ingressariam e sairiam 
da rede constantemente. Além disso, o interesse material seria secundário: o principal interesse dos participantes dessas redes seria o comprometimento intelectual ou emocional. Assim, o elemento que os manteria unidos na rede é o compartilhamento de uma base comum de informação e compreensão sobre uma política e seus problemas.

Os conceitos desenvolvidos por Heclo foram aprofundados por diversos autores durante as décadas seguintes (de $1980 \mathrm{em}$ diante), destacando a fragmentação e a ausência de um grupo (ou poucos grupos) dominante na produção de políticas públicas. Seguindo Heclo, estudiosos de agenda-setting se debruçaram sobre as definições de subsistemas, mas não sem antes efetuar importantes revisões. Keith Hamm (1983) foi o primeiro a aplicar de forma sistemática a pesquisa de Heclo para o estudo da formulação de políticas em âmbito federal. Como Heclo, Hamm chama atenção para um processo político altamente descentralizado, composto de "subgovernos" numerosos e complexos. $O$ autor se concentra nas relações entre os comitês do Congresso, grupos de interesse e agências federais, e sua pesquisa indica que esses grupos trabalham em estreita colaboração na formação de políticas públicas, muitas vezes produzindo políticas em seu próprio benefício. Ainda que o processo de política seja caracterizado de forma mais descentralizada, quando comparado ao modelo de "triângulo de ferro", a proposta de Hamm se afasta do modelo pluralista quando o autor sugere que as subunidades especializadas continuam a desempenhar um papel central na produção de políticas.

O conceito de issue networks e os estudos que procuraram aprimorar a noção de subsistemas de política produziram mudanças no entendimento de que um único grupo de atores, bastante fechado e inacessível, possa exercer influência direta sobre os problemas abordados pelo governo. No entanto, esses modelos não necessariamente apoiam um modelo pluralista do processo político. Em vez disso, as elites - ou technopols, para usaro termo de Heclo, ou committeestaff, como sugerido por Hamm - bem como os grupos organizados - ainda exercem uma parcela desproporcional de poder indireto no processo de políticas públicas e nas tomadas de decisão.

Outra influente perspectiva desenvolvida a partir do conceito de redes de Heclo é a proposta de Rhodes (1988), que desenvolve a ideia de redes de políticas públicas (policy networks). Para Rhodes, as origens da ideia de rede residem na perspectiva pluralista desenvolvida pelos estadunidenses e na literatura sobre os subgovernos. Tal perspectiva permitiu o desenvolvimento de explicações sobre o relacionamento entre o Estado e os diferentes grupos que buscam influenciar a produção de políticas públicas, por um lado, e o interesse do próprio Estado em obter apoio desses grupos. Tais padrões de relacionamento, aponta o autor, se institucionalizam e se tornam parte do dia a dia das 
organizações públicas: "eles [os grupos] são consultados antes que documentos sejam enviados para consulta. Eles não fazem lobby. Promovem almoços. Esses padrões rotineiros, estandardizados de interação entre governo e interesses de grupo se tornam redes de políticas" (Rhodes, 2008,p.427).Assim, as redes representam uma abordagem que, de certa forma, rompe com a dicotomia Estado-sociedade, ao entender que atores pertencentes aos quadros governamentais são também atores sociais e mantêm relações constantes com outros atores numa rede de relacionamentos.

Outro conceito, bastante relacionado à ideia de redes, éo de comunidades de políticas públicas (policy communities), que se desenvolve entre os anos 1970 e 1980, sobretudo no contexto do Reino Unido. Embora ainda não haja consenso na literatura a respeito de uma definição precisa sobre o termo, grande parte dos pesquisadores associa a ideia de comunidades de políticas ao modelo de Rhodes. As comunidades teriam as seguintes características principais: participação limitada, alta integração entre os membros, consistência ao longo do tempo, controle de recursos e distribuição balanceada de poder.

Uma comunidade de politicas tem as seguintes características: um número limitado de participantes com alguns grupos conscientemente excluídos; interação frequente e de alta qualidade entre todos os membros da comunidade em todos os assuntos relacionados com as questões das políticas; coerência em valores, filiação e resultados das políticas que persistem ao longo do tempo; consenso, com a ideologia, valores e preferências políticas gerais compartilhados por todos os participantes; e relações de troca com base no controle de alguns recursos por todos os membros da comunidade de politicas. Assim, a interação básica envolve a negociação entre os membros com recursos. Há um equilíbrio de poder, não necessariamente aquele em que todos os membros se beneficiam igualmente, mas aquele em que todos os membros se veem em um jogo de soma positiva. As estruturas dos grupos participantes são hierárquicas para que os líderes possam garantir membros cooperativos. Este modeloéum tipo ideal;nenhuma área de políticas públicas é propensa a se conformar exatamente a ele. (Rhodes, 2008, p.427)

As comunidades configurariam um extremo da rede de políticas públicas, sendo o outro extremo caracterizado pelas redes temáticas (issue networks). Segundo Rhodes, as redes temáticas têm participação ampla, baixa integração entre os membros, ausência de consenso, conflito e relações assimétricas de poder entre os integrantes.

As redes temáticas são caracterizadas por: existência de muitos participantes; interação e acesso flutuantes para os vários membros; ausência de consenso e presença de conflitos; interação com base em consultas em vez de 
negociação ou barganha; uma relação desigual de poder em que muitos participantes podem ter poucos recursos, pouco acesso e nenhuma alternativa. (Rhodes, 2008,p.428)

Assim, as comunidades configuram, para Rhodes, uma modalidade específica de rede, caracterizada por alta integração e padrões densos de relacionamento entre os atores. No entanto, apesar da diferenciação proposta pelo autor, a literatura especializada ainda não registra consenso em relação à aplicação dos conceitos de redes e comunidades (Miller e Demir, 2007).

Apesar das imprecisões conceituais, a perspectiva de redes e comunidades de políticas tem se expandido na literatura de políticas públicas, sobretudo a partir dos anos 1990. Em tais abordagens, os diferentes tipos de relacionamento estabelecidos entre os diversos atores (estatais e não estatais), desenvolvidos num contexto institucional específico, explicam as formas pelas quais o sistema político produz as políticas públicas. Explicar como os relacionamentos que se estabelecem nas comunidades e redes são formados e como são alterados ao longo do tempo, gerando mudanças nas políticas públicas, é o desafio dos principais modelos de análise em políticas públicas na atualidade. Nas próximas seções, buscaremos apontar como três modelos que se apoiam nessa perspectiva têm lidado com essa questão.

\section{SUBSISTEMAS E AS COMUNIDADES DE POLÍTICAS NO MODELO DE MÚLTIPLOS FLUXOS}

A abordagem proposta por John Kingdon (2003) para explicar mudanças na agenda governamental (agenda-setting) não só contribuiu para ampliar a compreensão sobre o processo de produção de políticas públicas em relação ao momento da formulação, mas auxiliou no entendimento de aspectos mais amplos do processo político, como a natureza "anárquica" da tomada de decisão em organizações burocráticas e a dimensão das ideias e dos atores organizados em torno de comunidades de políticas.

As comunidades de políticas são centrais ao modelo de Kingdon, configurando um elemento primordial para a análise política. $\mathrm{O}$ autor as caracteriza como um conjunto de especialistas que atuam numaárea específica (saúde, educação, habitação, transporte etc.). Tais especialistas podem fazer parte do governo, como assessores parlamentares, servidores do Poder Executivo ligados a atividades de planejamento, orçamento, ou a áreas funcionais. Da mesma forma, os especialistas podem integrar consultorias, grupos de interesse ou universidades, em organizações estatais ou não. Em comum, os especialistas compartilham preocupações com relação a uma determinada área de política. 
Em algumas comunidades, as interações se processam de forma coesa e integrada, como relata Kingdon (2003) em suas experiências de entrevistas com membros de comunidades.

Kingdon mostra que esses padrões de interação, presentes nas comunidades, têm influência sobre a forma como as políticas são produzidas em cada área. Em áreas de políticas nas quais comunidades são mais coesas (como no caso da saúde), os integrantes compartilham perspectivas, orientações e referenciais mais gerais sobre os temas que os unem. Dessa forma, os entendimentos são compartilhados e a comunidade se torna cada vez mais integrada. Por outro lado, em comunidades fragmentadas (como no exemplo dos transportes), a ausência de um entendimento comum torna as próprias comunidades também mais instáveis. Como resultado, a formulação das políticas de saúde tende a se apresentar de forma mais estruturada, o que facilita seu ingresso na agenda, ao contrário das questões oriundas de comunidades mais fragmentadas, como no exemplo da área de transportes.

As comunidades são espaços importantes para a geração de ideias relativas a soluções e alternativas que podem ser desenvolvidas e adotadas como políticas públicas pelos tomadores de decisão. Muitos participantes apresentam em suas comunidades propostas sobre o que fazer sobre uma determinada questão. Algumas dessas propostas serão consideradas, enquanto outras serão descartadas pelo próprio grupo. Propostas viáveis tecnicamente e adequadas aos valores do grupo e do mundo político acabam alcançando consenso dentro de uma comunidade. Portanto, as comunidades representam um importante espaço de experimentação, debate e difusão de ideias.

É importante destacar que as comunidades funcionam de forma independente do calendário eleitoral e das mudanças nos postos de comando da alta burocracia, e também não são diretamente afetadas pelas pressões da opinião pública sobre a ação governamental. As ideias geradas nas comunidades não estão necessariamente ligadas a problemas a ser resolvidos pelo governo. O modelo, baseado em três processos (ou fluxos) que afetam a formação da agenda governamental - problemas, soluções e contexto político -, pressupõe certa independência entre esses três elementos. Assim, o modelo assegura às comunidades papel fundamental no desenvolvimento das ideias que podem ser adotadas pelos formuladores de políticas. A atividade das comunidades, entretanto, não é condição suficiente para que uma questão seja inserida na agenda governamental, uma vez que o modelo destaca a importância da confluência entre propostas (geradas pelas comunidades no fluxo de soluções), definição de problemas (no fluxo de problemas) e um contexto político favorável (fluxo político). Ou seja, as comunidades são fundamentais ao modelo, mas não explicam, por si sós, mudanças em políticas públicas. 
O modelo do equilíbrio pontuado foi proposto por Baumgartner e Jones (1993) para analisar longos períodos de estabilidade na produção das políticas públicas, nos quais as elites dominam uma área de política, e também rápidos períodos de mudança, nos quais não se verifica a preponderância dessas elites. Os autores partem da perspectiva de que o sistema político é estruturado em torno de arranjos que proporcionam benefícios contínuos para alguns grupos privilegiados. Tais arranjos (e os autores se referem especificamente à ideia de subsistemas) se formam devido ao processamento paralelo de decisões nas organizações públicas.

Os sistemas políticos, como os seres humanos, não podem considerar todos os problemas que enfrentam de forma simultânea. Assim, a existência de alguma forma de subsistema de políticas pode ser vista como um mecanismo que permite que o sistema politico se envolva em processamento paralelo. Milhares de questões podem ser consideradas simultaneamente em paralelo dentro de suas respectivas comunidades de especialistas. [...] O processamento paralelo de fato opera contra mudanças políticas maiores, porque tende a ser isolado dos holofotes da publicidade associada com a política do macrossistema. (True, Jones e Baumgartner, 1999, p. 100)

Os subsistemas, para os autores, constituem-se como comunidades de especialistas caracterizadas por participação limitada e mudanças lentas e incrementais. Há, no entanto, momentos em que algumas questões escapam ao processamento insulado nos subsistemas e acessam o macrossistema. "As questões não podem ser sempre consideradas nos limites de um subsistema de políticas; ocasionalmente intervêm forças macropolíticas" (True, Jones e Baumgartner, 1999, p. 100). O acesso de uma questão ao macrossistema é o momento em que as maiores mudanças numa política tendem a ocorrer, e isso geralmente se dá quando outros participantes se tornam interessados, podendo gerar, como consequência, mudanças nos próprios subsistemas.

Central ao modelo é o conceito, proposto pelos autores, de monopólios de políticas (policy monopolies). Tais monopólios são caracterizados por dois aspectos. Em primeiro lugar, um entendimento compartilhado - uma imagem (policy image) - a respeito da política de interesse. Quando um entendimento específico se torna dominante, os atores ganham a habilidade de controlar a interpretação sobre um problema e a forma como este é percebido e discutido. Tal imagem geralmente está associada a valores políticos e pode ser comunicada de forma simples e direta ao público, reforçando o controle do monopó- 
lio sobre a questão. Em segundo lugar, os monopólios são reforçados por arranjos institucionais que mantêm o processo decisório limitado a um grupo pequeno de atores, restringindo o acesso dos demais. Esses monopólios são responsáveis pela manutenção da estabilidade na produção de políticas públicas e pela restrição da inclusão de novas questões na agenda governamental.

Enquanto uma visão compartilhada sobre símbolos, problemas, soluções e relações causais a respeito de uma determinada política prevalecer, restringir-se-áo acesso ao processo decisório daqueles atores que não concordam com essa imagem. Tem-se, então, a prevalência de mudanças lentas, graduais e incrementais, configurando uma situação de equilíbrio na produção das políticas públicas. No entanto, em alguns momentos, novos atores conseguem acesso aos monopólios, criando instabilidade e a oportunidade de mudança na agenda. Isso geralmente acontece, segundo os autores, devido a mudanças na forma como uma questão é compreendida, ou seja, por meio de alterações na imagem de uma política. Mudanças na percepção das questões, acontecimentos que focalizem a atenção do governo, alterações na opinião pública, por exemplo, podem contribuir para a alteração na imagem de uma política, permitindo o acesso de diferentes grupos ao processo decisório e, dessa forma, favorecendo o acesso de novas questões à agenda governamental. Quando uma questão ascende ao macrossistema, o monopólio deixa de existir e o sistema se torna propenso à mudança, já que a atenção dos líderes governamentais e do público pode levar à introdução de novas ideias e de novos atores. As novas ideias e instituições tendem a permanecer ao longo do tempo (policy legacy), criando um novo estado de equilíbrio no sistema político, que, após um período, tende a voltar à estabilidade.

Assim, o modelo de equilíbrio pontuado toma como unidade básica de análise os monopólios de políticas, destacando a relação entre instituições, atores e ideias na estruturação de políticas. A abordagem desenvolvida por Baumgartnere Jones (1993) apresenta um desenvolvimento importante na literatura sobre os subsistemas, considerando não apenas a estabilidade característica destes, mas os mecanismos de mudanças que impactam a produção de políticas numa determinada área. Além disso, contribui para esclarecer as conexões entre o subsistema e o macrossistema político.

\section{SUBSISTEMAS E AS COALIZ̃̃es de DEFESA NO MOdELO dAS COALIZÕES DE DEFESA}

Inicialmente apresentado por Sabatier e Jenkins-Smith (1993), o modelo das coalizões de defesa (advocacy coalition framework - ACF) se propõe a analisar mudanças nas políticas públicas destacando o papel 
da informação técnica no processo de disputas que envolvem múltiplos atores em distintas esferas e níveis de governo (Sabatier e Weible, 2007).

Ao adotar o termo "coalizão", os autores indicam que os atores estão inseridos em um subsistema político, entendido pelos autores como o lócus onde ocorrem discussões e debates de múltiplos atores motivados pela defesa de suas crenças. Atores de diferentes origens e níveis de governo compartilham sistemas de crenças específicos e atuam coordenadamente com o objetivo de tornar os seus posicionamentos predominantes nos programas e políticas de governo.

$O A C F[$ advocacy coalition framework $]$ sugere que o nivele unidade de análise mais útil é o grupo, por exemplo, as coalizões em um subsistema de politicas definidas como um conjunto de agentes envolvidos com o mesmo problema. O que importa é entender como as coalizões são formadas, como adquirem recursos e desenvolvem crenças politicas, e como elas tentam influenciaras decisões de autoridadessoberanas. (Zahariadis, 1998, p.437)

Na perspectiva do modelo, as coalizões são geradas a partir de convicções, opiniões, ideias e objetivos dos atores envolvidos no processo do "fazer" política pública. Esse conjunto de ideais e convicções, unido aos recursos políticos, formata as coalizões e concretiza os objetivos e os interesses dos atores. São, portanto, as coalizões de defesa, dependendo de sua extensão e da natureza da política em causa, que determinam quais atores participam no sistema político (Sabatier e Weible, 2007).

Nesse processo, que busca influenciar a produção de políticas correspondentes às crenças dos grupos inseridos nos subsistemas, o modelo destaca o papel dos especialistas, entendidos como atores que podem orientar os processos de aprendizado dentro de coalizões de defesa e entre elas. $O$ aprendizado é beneficiado pela análise dos resultados e impactos das políticas, realimentando assim o subsistema através da modificação de crenças, convicções e recursos. Subsistemas interagem com os amplos sistemas social, econômico, legal e institucional na atualização de informações e na produção de novos conhecimentos. Isso significa dizer que, no nível macro, ainda que a maior parte dos processos de políticas ocorra entre especialistas dentro de um subsistema de política pública, seus comportamentos são afetados por fatores mais amplos presentes no amplo sistema político e socioeconômico, e suas decisões, em contrapartida, também afetam o macrossistema, não se limitando ao subsistema no qual estão inseridos (Sabatier e Weible, 2007).

Dessa forma, o conceito de coalizões parece se aproximar do significado de comunidades políticas ao assumir que a especializaçãoé tida 
como condição necessária para o indivíduo/grupo influir no processo de formulação de políticas.

Como o ACF [advocacy coalition framework] assume que a informação científica e técnica desempenha um papel importante em modificaras crenças dos participantes da política, ele, correspondentemente, assume que pesquisadores (cientistas universitários, analistas de políticas, consultores etc.) são alguns dos atores centrais em um processo de políticas. (Sabatiere Weible, 2007, p. 192)

São, portanto, a forte relação entre os membros, o compartilhamento e a coesão de valores, ideias e crenças, somados aos domínios técnicos e legais sobre políticas específicas (policy domain), que legitimam a participação dos atores e a formação de coalizões de defesa (Sabatier e Weible, 2007).

\section{A APLICAÇÃo dos CONCEITOS dE SUBSISTEMAS, REDES E COMUNIDADES: EXEM- PLOS EMPíricos NOS MOdELOS de MÚlTIPLOS flUXOS, EQUILÍBRO PONTUAdO E COALIZÕES DE DEFESA}

As divergências na utilização dos conceitos estão presentes mesmo entre os autores que desenvolvem suas análises com base nos modelos teóricos apontados anteriormente. Zahariadis (2003), por exemplo, entende que as comunidades de políticas consistem em um tipo específico de rede, mais estável e com maior restrição ao acesso de novos participantes, enquanto a noção de redes envolveria um conjunto amplo de atores em interações de caráter mais fluido. Assim, ele adota o conceito de redes para se referir ao que Kingdon chama de comunidades de políticas (Zahariadis, 2003, p.48). Em sua análise do processo de privatização na Grã-Bretanha, o autor examina a relação entre a estrutura das redes e a evolução da ideia de privatização, com base no modelo de Múltiplos Fluxos.

Zahariadis mostra que a rede que se estabeleceu em torno da reforma britânica era composta de atores (administradores, sindicatos, consumidores, entre outros) que apresentavam um nível bastante baixo de integração, característica definida a partir de quatro elementos: a) tamanho, uma vez que se tratava de uma rede grande, envolvendo diversos atores; b) modo de operação competitivo, no qual os atores não buscavam consensos e estabeleciam contatos aleatoriamente, dentro de uma lógica de oposição; c) capacidade de administração baixa, ou seja, atores com acesso limitado às ferramentas de implementação; d) alta permeabilidade da rede, caracterizada por acesso pouco restringido, tanto do ponto de vista interno (padrões de comunicação e influência entre os participantes de uma mesma rede) quanto externo 
(relações estabelecidas entre uma rede e as outras). Essas características da rede em torno da reforma foram, para o autor, fundamentais para o tipo de mudança que se observou na reforma britânica. As ideias sobre a privatização circularam em diversas redes ao longo do tempo. Mas, em algumas redes, as opções alternativas à transferência da propriedade estatal ao mercado foram consideradas mais seriamente do que em outras.

O autor mostra que o tamanho foi uma característica relevante e que proporcionou a subsistência das ideias ligadas à nacionalização das empresas. A rede em torno de diferentes políticas públicas ampliou-se com a inserção dos sindicatos e com o aumento da participação desses atores em comissões e comitês governamentais, o que reduziu as chances de a ideia de privatização prosperar como uma alternativa viável no fluxo de soluções. A participação dos trabalhadores na gestão e a representação dos sindicatos nos conselhos teriam pouco efeito em um cenário no qual a atividade privada orientasse a ação em diferentes setores da vida nacional. Por outro lado, grupos de consumidores organizaram-se e, muito embora tenham tido pouca influência sobre as políticas públicas, foram bem-sucedidos no acesso à rede, com o estabelecimento de conselhos consultivos. Alguns desses grupos influenciaram na criação de padrões de qualidade de produtos (como grupos ligados à carvoaria), enquanto outros foram decisivos para garantir a prestação de serviços para algumas comunidades (grupos ligados às ferrovias). Esses grupos tinham incentivos contrários à privatização, uma vez que essa mudança limitaria seus recursos de poder. Assim, o argumento do autor é que a ampliação da rede, a inserção e legitimação de novos atores por meio da participação em canais institucionais, sustentou a ideia de empresas estatais por um longo período.

Outra característica marcante da rede - seu modo de operação competitivo - permitiu a sobrevivência da ideia de privatização ao longo de décadas, porém os debates em torno da ideia não prosperaram durante décadas devido à própria competição entre atores dentro da rede, especialmente nos casos do aço e do transporte rodoviário de mercadorias. Apesar de a ideia da privatização estar presente nas redes, os sindicatos, o Partido Trabalhista, alguns ministros Conservadores e vários gerentes de empresas públicas foram atores importantes para que essa ideia não fosse entendida como uma opção viável no interior da rede. Esse cenário muda com a chegada de Thatcher ao poder, em 1979, quando a composição das redes é alterada e indivíduos favoráveis à ideia de privatização passam a ocupar cargos-chave em áreas estratégicas da administração (energia, indústria), enquanto aqueles contrários a essa ideia foram afastados. A baixa capacidade administrativa, ou seja, a limitação das soluções disponíveis para a im- 
plementação de políticas, relacionada ao modelo britânico, dificultou a resolução dos conflitos relativos às finanças das empresas públicas, e a ideia de privatização ganha larga aceitação depois de se esgotarem os arranjos de financiamentos impostos pela nacionalização. Assim, Zahariadis (2003) mostra que a estrutura das redes - considerada em termos da sua integração (tamanho, modo, capacidade e acesso) influenciou a trajetória das ideias desenvolvendo e fazendo avançar a concepção original de Kingdon sobre o fluxo de soluções.

Outro exemplo da aplicação dos conceitos de subsistemas, comunidades e redes vem do trabalho pioneiro de Baumgartner e Jones (1993). Como vimos, os autores concentram suas explicações na noção de monopólio de políticas públicas, e, embora eles tenham se dedicado à investigação de diversos casos nas mais diferentes áreas setoriais, o estudo sobre a política de energia nuclearébastante ilustrativo.

A construção de um monopólio em torno da política de energia nuclear desenvolveu-se nos Estados Unidos ao longo das décadas de 1940 e 1950, associada a uma imagem muito positiva sobre as questões nucleares, envolvendo elementos como a característica limpa dessa fonte de energia e a possibilidade de redução da poluição, o aspecto econômico da produção de energia impactando diretamente a redução das contas para os consumidores, a alta tecnologia envolvida e o desenvolvimento de uma fonte de energia de baixo custo para o futuro, reduzindo a dependência de outros países para obtenção de petróleo, entre outros aspectos. É certo que outras imagens sempre estiveram presentes, envolvendo aspectos negativos como o potencial altamente destrutivo das armas nucleares, interesses de empresas privadas, mutações genéticas, entre outros entendimentos, mas a visão positiva era, nesse período, muito mais presente. Membros do governo, da comunidade científica, jornalistas e empresas do setor privado estavam entre os atores que compartilhavam essa visão positiva. Além da imagem positiva, mudanças institucionais foram produzidas e permitiram aos defensores desse entendimento sobre a energia nuclear exercer controle sobre a política.AComissão de Energia Atômica, criada em 1946, tinha a responsabilidade de promover a regulação e o fomento da produção nuclear, bem como de produzir os itens militares associados à energia nuclear. Além da comissão, integraram o monopólio os construtores das centrais nucleares, a elite tecnocrática civil e militar e a Comissão Mista sobre Energia Atômica, comitê conjunto entre a Câmara e o Senado. Segundo os autores, o monopólio se manteve enquanto a imagem positiva perdurou e o controle sobre a questão permaneceu nas mãos da Comissão de Energia Atômica e da Comissão Mista.

Duas décadas depois, nos anos 1960 e 1970, o monopólio entraem colapso. Vários fatores contribuíram para sua dissolução. No interior 
da Comissão de Energia Atômica, diversos membros questionavam aspectos relacionados à segurança, levando à deserção de parte do grupo original.A questão se expande para além dos limites do monopólio e da Comissão de Energia Atômica quando cientistas compartilham as preocupações internas com segurança com outras organizações, previamente excluídas do debate e também relacionadas à temática. A imagem passa de positiva a negativa também na mídia, que destaca elementos até então ausentes, como preocupações com a segurança e com possíveis impactos negativos ao meio ambiente, e cristaliza-se com o acidenteem Three Mile Island, no estado da Pennsylvania, ocorrido em 1979. Paralelamente, novos atores começaram a demandar o controle sobre a questão da energia nuclear, o que pode ser observado com o aumento do número de comitês e subcomitês no Congresso voltados sobretudo a ações de controle da energia nuclear. Em 1974 a Comissão de Energia Atômica foi desmantelada e suas funções regulatórias passaram a ser atribuídas à Comissão Regulatória Nuclear, sendo as demais funções direcionadas para a Agência de Pesquisa e Desenvolvimento Energéticos. Assim, o monopólio em torno da política nuclear - envolvendo tanto os entendimentos a respeito da questão quanto as instituições construídas para lhe dar suporte - foi destruído. Nas décadas seguintes, a imagem negativa em torno da questão permaneceu, e até recentemente a energia nuclear não era uma opção seriamente considerada pelos tomadores de decisão.

No modelo de Coalizões de Defesa, o conceito de subsistemas é aplicado por meio da noção de coalizões que abrangem ideias, interesses e crenças. Em um estudo que busca mapear as coalizões existentes e suas formas de interação na área ambiental, Sabatier e Basher (1993) analisaram 190 depoimentos em audiências legislativas e administrativas cujo tema era o uso da terra e a política de qualidade da água na bacia de Lake Tahoe (Califórnia e Nevada) entre os anos de 1960 e 1984. Nesse estudo, os autores demonstram como um cenário bastante fluido dos anos 1960, em que os múltiplos atores não se reuniam em torno de nenhum tipo de associação ou comunidade nem tinham interesses comuns sobre questões locais, transformou-se, a partir de fusões de grupos difusos, em duas coalizões bem delimitadas e muito distintas em meados dos anos 1970. A primeira coalizão foi denominada Coalizão de Propriedade Econômica e era composta de funcionários de governos locais, gestores públicos na bacia de Lake Tahoe, empresários locais, líderes de grupos de direitos de propriedade e vários legisladores (em especial de Nevada). Do outro lado, a Coalizão Ambiental, adversária, era composta de grupos de ambientalistas locais e estaduais, funcionários de várias agências de controle de poluição, tanto da Califórnia quanto de Nevada, diversos pesquisadores, acadêmicos e legisladores da Califórnia. A análise desse estudo 
de caso demonstrou como o subsistema Tahoe se transformou ao longo de pouco mais de uma década. Inicialmente caracterizado por um consenso vago, difuso e sem estratégias definidas de planejamento ambiental regional, o subsistema transformou-se em uma arena em que duas coalizões foram formadas a partir de um sistema de crenças comuns, defendendo distintas formas de atuação para a solução de problemas locais relativos ao uso da água e do solo.

CONSIDERAÇões FinaIS

O presente estudo procurou apresentar e discutir o histórico e as transformações nos conceitos de subsistemas, redes e comunidades de políticas públicas, apontando para a incorporação desses elementos como mecanismos centrais em modelos mais recentes de análise de políticas públicas. A revisão dessas questões nos dá uma melhor noção sobre o que esses conceitos podem, ou não podem, explicar. $\mathrm{O}$ conceito de subsistemas se refere às nossas instituições sociais e à forma como elas interagem umas com as outras e com entidades e atores não governamentais, tais como grupos de interesse, a mídia e especialistas em política. Nesse sentido, a revisão histórico-conceitual proposta na primeira parte do artigo aponta para uma das questões de investigação mais significativas inseridas nesse contexto: 0 papel dos subsistemas na análise de políticas públicas. Como visto, as principais mudanças, a partir da noção tradicional de triângulos de ferro para os conceitos mais atuais de redes, comunidades e coalizões, estão relacionadas à forma como o conflito se estabelece, aos atores envolvidos e às dinâmicas internas que operam o processo de construção de políticas.

Os três modelos aqui analisados - Multiple Streams Model, Punctuated-Equilibrium Model e Advocacy Coalition Framework - tomam esses conceitos como base, embora analisem de forma distinta suas influências no processo político. No modelo de Kingdon (2003), o conceito de comunidade de políticas (policy community) recebe especial ênfase, particularmente em processos de definição de alternativas. No entanto, o autor denomina comunidades também os grupos menos coesos (o que poderia ser compreendido, na perspectiva de Rhodes, como uma rede temática - e não propriamente uma comunidade). Kingdon mostra que o grau de coesão de uma comunidade é uma característica importante, pois acarreta consequências para o processo político. $\mathrm{O}$ modelo apresenta as comunidades como elemento responsável por um dos três fluxos da formulação de uma política pública, com destaque para a atuação de especialistas reunidos em torno de um tema vinculado a uma área temática e do compartilhamento de ideias entre eles. No modelo de Sabatier e Jenkins-Smith (1993), os subsistemas são 
compostos de diversas coalizões, formadas por atores governamentais e não governamentais. As coalizões contemplam os especialistas, suas ideias e crenças e ainda os interesses dos grupos em disputa. Os interesses e crenças também constituem a base dos monopólios de políticas, no modelo de Baumgartner e Jones (1993). Tal conceito é empregado para auxiliar na explicação de processos de mudança e também de estabilidade na produção de políticas públicas. Assim, os três modelos destacam a o papel das ideias e dos interesses nos subsistemas, desenvolvendo conceitos complementares em cada caso. $\mathrm{O}$ foco predominante dessa literatura reside, portanto, nas interações entre diferentes atores, instituições e ideias no âmbito dos subsistemas. Ainda que não exista na literatura um consenso a respeito desses conceitos, uma característica parece evidente:entendidas como partes integrantes dos subsistemas de políticas, comunidades e redes passaram a ser consideradas como unidade de análise privilegiada em abordagens recentes sobre o processo de políticas. Segundo Sabatier, o conceito de subsistemas é uma contribuição distintiva para a teorização do processo de políticas públicas (Sabatier, 1991).

Entretanto, ainda que o conceito de subsistemas tenha ganhado relevância e seja frequentemente aplicado para entender a produção de políticas nos contextos estadunidenses e europeus, estudos recentes indicam que, ao adotar os subsistemas como unidade básica de análise, os estudiosos de políticas públicas têm, em grande parte, ignorado as possibilidades e os desafios impostos pela dinâmica dos cross-subsystems. Segundo essa crítica, ainda que se reconheça a existência de sobreposição de comunidades e redes em diferentes subsistemas (McCool,1989; Jochime May, 2010; Sabatier, 1998), a literatura sobre o processo de políticas públicas ainda tem muito pouco a dizer sobre essa dinâmica política que envolve vários subsistemas (Jochim e May, 2010). Assim, um dos desafios teóricos a ser superados pela literatura diz respeito às relações entre diferentes subsistemas, contribuição que pode fazer avançar a pesquisa, possibilitando um melhor entendimento sobre a dinâmica das interações entre instituições, atores e suas ideias na produção de políticas públicas.

\section{REFERÊNCIAS BIBLIOGRÁFICAS}

Baumgartner, Frank R., e Jones, Bryan D. Agendas and instability in American politics. Chicago: University of Chicago Press, 1993.

Birkland, Thomas A. An introduction to the policy process:theories, concepts, and models of public policy making. 2.ed. Nova York: ME Sharpe, 2005.

Freeman, J. Leiper. The political process: executive-bureau-legislative committee relations. Nova York: Random House, 1955.

Griffith, Ernest. The impasse of democracy. Nova York: Harrison Hilton Books, 1939. 
Hamm, Keith. "Patterns of influence among committees, agencies, and interest groups". Legislative Studies Quaterly VIII, 1983. In: McCool, Daniel. Public policy theories, models, and concepts: an anthology, 1994.

Heclo, Hugh. "Issue networks and the executive establishment". In: King, Anthony (ed.). The new American political system. Washington, DC: American Enterprise Institute for Public Policy Research, 1978 .

Howlett, Michael e Ramesh, M.Studying publicpolicy:policy cycles and policy subsystems. Oxford: Oxford University Press, 2003. . "Policy subsystem configurations and policy change: operationalizing the postpositivist analysis of the politics of the policy process". Policy Studies Journal, vol. $26, \mathrm{n}^{\circ} 3$, 1998 (466-481).

Jochim, Ashley E. e May, Peter J. "Beyond subsystems: policy regimes and governance". The Policy Studies Journal, vol. 38, n 2, 2010.

Kingdon, John. Agendas, alternatives, and public policies. 3. ed. Nova York: Harper Collins, 2003[1984].

McCool, Daniel. Public policy theories, models, and concepts: an anthology. Nova Jersey: Prentice-Hall, 1995.

Miller, Hugh T. e Demir, Tansu. "Policy communities". In: Fischer, F., Miller, G.J., e Sidney, M.S.S. (eds.). Handbook of public policy: theory, politics and methods. Boca Raton: CRC Press, 2007.

Peters, Guy B.American public policy. Nova York: MacMillan, 1986.

Rhodes, R.A.W.Beyond Westminster and Whitehall: the sub-central governments of Britain. Londres: Unwin Hyman, 1988. .Policy network analysis". In: Moran, M., Rein, M., e Goodin, R.E. (eds.). The Oxford handbook of public policy. Oxford: Oxford University Press, 2008.

Rhodes, R. A. W. e Marsh, D. "Policy networks in British politics: a critic of existing approaches". In: Marsh, D., e Rhodes, R.A.W (eds). Policy Networks in British Government. Oxford, Oxford University Press, 1992.

Ripley, Randall B., e Franklin, Grace A. Congress, the bureaucracy, and public policy. Chicago: Dorsey Press, 1984.

Sabatier, PaulA. "The advocacy coalition framework: revisions and relevance for Europe". Journal of European Public Policy, vol. 5, n ${ }^{\circ} 1,1998$ (pp. 98-130). . "Toward better theories of public policy”.PS:Political Science and Politics, 24, 1991 (pp.147-56).

Sabatier, Paul A., e Basher, Anne. In: Jenkins-Smith, Hank C. Policy change and learning: an advocacy coalition approach. Oxford: Westview Press, 1993.

Sabatier, Paul A., e Jenkins-Smith, Hank C. Policy change and learning: an advocacy coalition approach. Oxford: Westview Press, 1993. 
Sabatier, Paul A., e Weible, Christopher M. "The advocacy coalition:innovations and clarifications". In:Sabatier,P.(ed.). Theories of the policy process. 2.ed. Boulder, CO: Westview Press, 2007.

Thurber, James A. "Political power and policy subsystems in American politics". In: Peters, Guy, e Rockman, Bert A. (eds.). Agenda for excellence: administering the state. Chatham/NJ: Chatham House Publishers, 1996.

True, James L., Jones, Brian D., e Baumgartner, Frank R. "Punctuated-equilibrium theory: explaining stability and change in American policymaking". In: Sabatier, Paul A. (ed.). Theories of the policy process. Oxford:Westview Press, 1999.

Zahariadis, Nikolaos. "Comparing three lenses of policy choice". Policy Studies Journal, v. 26, n 3, 1998 (pp.434-448).

. Ambiguity $\&$ choice in public policy.

Washington: Georgetown University Press, 2003.

Recebido para publicaçao em 14 de

maio de 2015.

\section{NOVOS ESTUDOS}

CEBRAP

101 , março 2015

pp. $57-76$

ANA CLÁUdiA NiEDHARDT CAPEllaé professora do Departamento deAdministração Pública da Unesp Araraquara e professora colaboradora do Programa de Pós-Graduação em Ciência Política da UFSCar.(acapella@terra.com.br)

FELIPE GonçAlves Brasilé doutorando do Programa de Pós-Graduação em Ciência Política da UFSCare bolsista FAPESP.(felipe.brasil@usp.br) 